\title{
Lupus Anticoagulant Sensitive APTT Measurement
}

National Cancer Institute

\section{Source}

National Cancer Institute. Lupus Anticoagulant Sensitive APTT Measurement. NCI

Thesaurus. Code C102277.

The determination of the amount of time that it takes for clotting to occur when a lupus sensitive reagent is added to a plasma specimen. 